\section{Post-transfusion Hepatitis}

The incidence of hepatitis with clinical jaundice in patients who have received an average of two bottles of blood is 1 in $200,{ }^{1}$ and when ten or more bottles are given, as in open heart surgery, jaundice follows in 1 in 10 patients. ${ }^{2}$ The quantity of infected plasma that can transmit hepatitis may be as little as one millionth of a millilitre. ${ }^{3}$

The incidence of overt jaundice, however, gives too low an estimate of the frequency of hepatitis after transfusion of blood or blood products. Elevation of serum levels of both aspartate transaminase (S.G.O.T.) and alanine transaminase (S.G.P.T.) was found in 10 out of 56 patients receiving an average of 2 bottles of blood ${ }^{4}$; liver biopsy showed evidence of hepatitis in the six patients who consented to the procedure. This high attack rate implies that carriers of either hepatitis virus $\mathrm{A}$ or $\mathrm{B}$ are relatively frequent among healthy donors. Both R. F. Norris and his colleagues ${ }^{5}$ and J. G. Allen ${ }^{6}$ have shown that hepatitis is much more frequent when blood from chronic alcoholics or from inmates of prisons is used.

What can be done to reduce this hazard ? First and foremost it should be more widely known that a clear hazard exists and that the transfusion of a bottle of blood is a serious event. Allen ${ }^{6}$ cites the patient who was given a bottle of blood because there was a transient fall of blood-pressure during spinal anaesthesia given for an appendicectomy. This patient died from hepatitis seven weeks later. The surgeon who insists that the haemoglobin concentration be brought from $93 \%$ to $100 \%$ before his operating session is as culpable as the physician who treats simple iron deficiency anaemia with transfusion. Allen ${ }^{6}$ points out that more than half the patients receiving blood are given only 1 or 2 bottles, and if most of these transfusions were eliminated the number of patients at risk would be more than halved. Furthermore, two or three bottles of blood should not be given when one or two would suffice.

The second line of approach is to eliminate high risk donors. This has proved of importance in the United States, where the so-called "skid-row" population tend to become professional donors ; in this group the incidence of carriers of virus hepatitis has been shown to be at least 10 times that in volunteer donors. ${ }^{6}$ It is the practice not to accept as donors those known to have been jaundiced. The feasibility of screening donors by liver function tests was explored by D. R. Fitch and his colleagues, ${ }^{7}$ who found $30 \%$ of healthy donors showed either minor or more evident variation from the normal. Since this does not mean that one-third of these donors necessarily carried the virus, their exclusion seems hardly justifiable. However, Norris and his team ${ }^{5}$ felt that such tests were desirable in the group of professional donors.

Further precautions are possible in the preparation of plasma when it is to be given either as such or used for the

\footnotetext{
1 Lehane, D., Kwantes, C. M. S., Upward, M. G., and Thomson, D. R., Brit. med., ., 1949, 2, 572.

${ }^{2}$ Holland, P. V., Rubinson, R. M., Morrow, A. G., and Schmidt, P. J., 7. Amer. med. Ass., 1966, 196, 471.

3 Murray, R., Bull. N.Y. Acad. Med., 1955, 31, 341

Hampers, C. L., Prager, D., and Senior, J. R., New Engl. f. Med., 1964, 271, 747.

Norris, R. F., Potter, H. P., and Reinhold, J. G., Transfusion (Philad.), 1963, 3, 202.

- Allen, J. G., Ann. Surg., 1966, 164, 475.

" Fitch, D. R., Watanabe, R. K., Kassouny, D., Neefe, J. R., Reinhold, J. G., and Norris, R. F., Amer. F. clin. Path., 1955, 25 , 158 .

- Allen, J. G., Dawson, D., Sayman, W. A., Humphreys, E. M., Benham, R. S., and Havens, I., Ann. Surg.,

10 Grossmann, H., Zbl. Gynak., 1924, 48, 2065. 1965, 273, 59.
}

preparation of blood products. The use of small plasma pools is widely accepted. However, attempts to sterilize plasma in a way that does not denature the protein have been less successful. Ultraviolet irradiation, chemical additives, and prolonged storage at various temperatures reduce the infectivity of the virus but do not eliminate the danger. ${ }^{8}$

Finally, $\gamma$-globulin given in the week following transfusion and again a month later was found to give between a fourfold and an eightfold reduction in the incidence of hepatitis. ${ }^{910}$ However, more recently P. V. Holland and his co-workers ${ }^{2}$ failed to show any benefit from $\gamma$-globulin in patients undergoing heart surgery. They gave the initial dose of $\gamma$-globulin simultaneously with the transfusion and they suggested that this may have interfered with the subsequent antibody response. Clearly more information on this point is required.

\section{An Obsolete Term}

There are certain descriptive terms used in clinical medicine which once learnt by the student are rarely forgotten, and among these is globus hystericus. It was introduced ${ }^{12}$ to describe patients believed to have a primary functional disturbance of swallowing, who had a sensation of obstruction at the top of the oesophagus and secondary anaemia. Later it was realized ${ }^{3}$ that in most of these patients the primary disorder was iron deficiency anaemia, and in retrospect many would now be considered to have sideropenic dysphagia. So primary psychogenic dysphagia with anaemia developing secondarily from nutritional deficiency became discounted as a syndrome.

The history of globus hystericus emphasizes the danger of diagnosing hysterical illness in disorders of obscure causation, and indeed it has been shown by E. Slater ${ }^{4}$ that in most patients thought to be suffering from hysteria there is organic disease or a non-hysterical psychiatric disorder.

Though no reference to globus hystericus can be found in at least one standard reference book on gastroenterology, ${ }^{5}$ the use of the term dies hard, and there is still a temptation to make use of it as a diagnostic label when there is no obvious organic cause for dysphagia. The penalties for doing so can be severe. K. G. Malcomson ${ }^{6}$ described four patients in whom a misdiagnosis of this disorder had been made; two had postcricoid carcinoma, one had a perforation of a peptic ulcer in a hiatus hernia, and one had carcinoma of the stomach affecting the cardia. All four died. Both in normal persons and in patients suffering from anxiety or depression emotional disturbance can give rise to a sensation of a lump in the throat (globus pharyngis), but food can be swallowed without difficulty. Even in this group of patients radiological examination will often reveal lesions, such as hiatus hernia and peptic ulcer, ${ }^{6}$ the existence of which was previously unsuspected.

The lesson is clear. When a patient complains of a lump in the throat, and especially when dysphagia coexists, a barium swallow and meal should be performed, together with endoscopic examination if necessary. Dysphagia is not a symptom likely to be produced by an emotional illness, and an organic cause should always be sought.

\footnotetext{
1 Vinson, P. P., Minn. Med., 1922, 5, 107.

Moersch, H.'J., and Conner, H. M., Arch. Otolaryng., 1926, 4, 112

? Witts, L. J., Guy's Hosp. Rep., 1931, 81, 193.

- Slater, E., Brit. med. F., 1965, 1, 1395.

Slater, E., Brit. med. G., 19rology, 1963, Vol. 1, 2nd ed. London.

- Backus, H. L., Gastroenterology, 1960, 1966, 39, 583.
} 